\title{
VAZÃO DE GOTEJADORES COM DISTINTOS TEMPOS DE IRRIGAÇÃO APLICANDO ÁGUA RESIDUÁRIA DE SUINOCULTURA E ÁGUA DE ABASTECIMENTO ${ }^{1}$
}

\author{
RAFAEL O. BATISTA ${ }^{2}$, RUBENS A. DE OLIVEIRA ${ }^{3}$, VLADIMIR B. FIGUEIREDO ${ }^{4}$, \\ KETSON B. DA SILVA ${ }^{5}$, DAIANNI A. DA COSTA FERREIRA ${ }^{6}$
}

\begin{abstract}
RESUMO: Este trabalho objetivou analisar o efeito das proporções do tempo de irrigação com água residuária de suinocultura (ARS) e água de abastecimento (AA) na alteração da vazão de gotejadores. $\mathrm{O}$ experimento foi montado no esquema de parcelas subsubdivididas, em delineamento inteiramente casualizado, com três repetições, tendo nas parcelas as proporções de tempo de irrigação (1E3A - 1 h de ARS e 3 h de AA; 2E2A - 2 h de ARS 2 h de AA; 3E1A - 3 h de ARS e 1 $\mathrm{h}$ de AA, e 4E - 4 h de ARS); nas subparcelas, os tipos de gotejadores (G1, G2 e G3) e nas subsubparcelas os tempos das avaliações $(0 ; 20 ; 40 ; 60 ; 80 ; 100 ; 120 ; 140$ e 160 h). Os atributos físicoquímicos e biológicos da ARS e AA foram obtidos a cada 20 h e 80 h, respectivamente. Realizou-se a medição de vazão nos 22 gotejadores identificados de todas as linhas laterais das unidades de irrigação, também a cada 20 h. Após 160 h, gotejadores e linhas laterais foram dissecados para investigação do material de obstrução. A combinação dos gotejadores G1 e G3 com as proporções de tempo de irrigação 1E3A e 4E minimizou o processo de entupimento, sendo as reduções nos valores de vazão de 16 e 8\%, respectivamente, após 160 h de operação das unidades de irrigação.
\end{abstract}

PALAVRAS-CHAVE: emissores, obstrução, efluente.

\section{DRIPPERS FLOW RATE WITH DIFFERENT IRRIGATION TIMES APPLYING SWINE WASTEWATER AND SUPPLY WATER}

\begin{abstract}
This study aimed to analyze the effect of the proportion of time irrigation with swine wastewater (ARS) and supply water (AA) on alteration of drippers flow rate. The experiment was set up on split-split-plot scheme with proportions of irrigation time of ARS and AA (1E3A - $1 \mathrm{~h}$ of ARS and $3 \mathrm{~h}$ of AA, 2E2A - $2 \mathrm{~h}$ of ARS and $2 \mathrm{~h}$ of AA, 3E1A - $3 \mathrm{~h}$ of ARS and $1 \mathrm{~h}$ of AA and $4 \mathrm{E}$ $4 \mathrm{~h}$ of ARS) in the plot, kind drippers (G1, G2 and G3) in the subplots and the operation time $(0,20$, $40,60,80,100,120,140$ and $160 \mathrm{~h}$ ) in the sub-subplots on an entirely randomized design, with three replicates. The physico-chemical and biological characteristics of ARS and AA were obtained every $20 \mathrm{~h}$ and $80 \mathrm{~h}$, respectively. The flow rate was determined in 22 drippers of each lateral line, also, every $20 \mathrm{~h}$. After $160 \mathrm{~h}$, drippers and lateral line were dissected to investigate the material of obstruction. The combination of drippers G1 and G3 with the proportions of irrigation time 1E3A and $4 \mathrm{E}$ minimized clogging process, where the reduction on flow rate values were of 16 and $8 \%$, respectively, after $160 \mathrm{~h}$ of operation of the irrigation units.
\end{abstract}

KEYWORDS: emitters, clogging, effluent.

\footnotetext{
${ }^{1}$ Trabalho extraído de tese de doutorado.

${ }^{2}$ Eng ${ }^{\circ}$ Agrícola, Prof. Dr., Depto. de Ciências Ambientais e Tecnológicas, UFERSA/Mossoró - RN, Fone: (84) 33171584, rafaelbatista@ufersa.edu.br.

${ }^{3}$ Eng $^{\circ}$ Agrícola e Eng ${ }^{\circ}$ Agrônomo, Prof. Dr., Depto. de Engenharia Agrícola, UFV/Viçosa - MG, rubens@ufv.br.

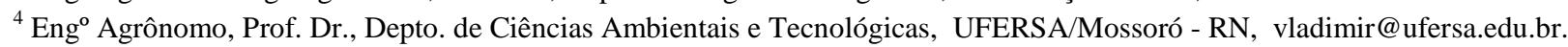

${ }^{5}$ Eng $^{\circ}$ Agrônomo, Depto. de Ciências Ambientais e Tecnológicas, UFERSA/Mossoró - RN, ketsonbruno@hotmail.com.

${ }^{6}$ Bacharel em Química Industrial, Depto. de Ciências Ambientais e Tecnológicas, UFERSA/Mossoró -

RN, daianniariane@ufersa.edu.br.

Recebido pelo Conselho Editorial em: 01-3-2012

Aprovado pelo Conselho Editorial em: 10-6-2014
} 


\section{INTRODUÇÃO}

A suinocultura brasileira passou por profundas alterações tecnológicas nas últimas décadas, visando principalmente ao aumento de produtividade e à redução dos custos de produção. Quando os dejetos de suínos são utilizados de forma criteriosa na agricultura, eles podem melhorar a qualidade do solo com a incorporação de matéria orgânica e propiciar a economia de adubos químicos devido ao aporte de macro e micronutrientes essenciais ao desenvolvimento de cultivos agrícolas (RODRIGUES et al., 2010).

O método de irrigação localizada é usado para aplicação de águas residuárias, em razão da elevada eficiência de aplicação do efluente e do baixo risco de contaminação, tanto do produto agrícola quanto de operadores no campo (BATISTA et al., 2011).

Por outro lado, nos sistemas de irrigação localizada, os emissores apresentam alta suscetibilidade ao entupimento. A sensibilidade ao problema de entupimento varia com as características do gotejador (ZHANG et al., 2010) e com a qualidade da água relacionada aos aspectos físicos, químicos e biológicos (CUNHA et al., 2006; DAZHUANG et al., 2009).

A formação de biofilme consiste na principal causa de entupimento de gotejadores que operam com águas residuárias (BATISTA et al., 2010; DAZHUANG et al., 2009). BATISTA et al. (2010) estudaram a formação de biofilme resultante da interação entre mucilagens bacterianas e algas e observaram que as bactérias dos gêneros Clostridium, Bacillus, Pseudomonas e Enterobacter formaram um muco microbiano, que foi aderido por partículas, principalmente de origem orgânica, representadas por células de algas vivas ou em decomposição.

O entupimento dos gotejadores reduz a eficiência dos sistemas de irrigação, afetando suas características de operação e exigindo manutenções mais frequentes. Geralmente, a obstrução reduz a vazão e, consequentemente, diminui a uniformidade de aplicação de água de sistemas de irrigação localizada (DAZHUANG et al., 2009; DURAN-ROS et al., 2009).

O nível de tratamento das águas residuárias reflete diretamente na sensibilidade ao entupimento dos gotejadores (PUIG-BARGUÉS et al., 2005; BATISTA et al., 2011). Segundo PUIG-BARGUÉS et al. (2005), o esgoto doméstico terciário proporciona menos problemas de entupimento de gotejadores em relação ao esgoto doméstico secundário. Entretanto, no trabalho realizado por BATISTA et al. (2011), verificou-se que os esgotos domésticos preliminar e terciário causaram maiores reduções na vazão dos gotejadores em relação ao esgoto doméstico secundário, devido à maior concentração de sólidos suspensos que interagiram com as mucilagens bacterianas.

Diante do exposto, este trabalho objetivou analisar o efeito de diferentes proporções de tempo de irrigação com água residuária de suinocultura e água de abastecimento na alteração da vazão de gotejadores.

\section{DESCRIÇÃO DO ASSUNTO}

O presente estudo foi motivado pelo efeito do nível de tratamento concebido às águas residuárias na obstrução de gotejadores, sendo que as condições de aerobiose ou anaerobiose do fluído interferem nesse processo, como descrito por PUIG-BARGUÉS et al. (2005) e BATISTA et al. (2011). Este trabalho foi conduzido de 2 de agosto a 10 de setembro de 2006, na Unidade-Piloto de Tratamento e Aplicação Localizada de Água Residuária de Suinocultura (UTARS), da Universidade Federal de Viçosa (UFV), em Viçosa-MG, sob as coordenadas geográficas $20^{\circ} 46^{\prime} 11.25 "$ de latitude sul e $42^{\circ} 51^{\prime} 44.96 "$ de longitude oeste.

Uma plataforma de testes foi construída de alvenaria, nas dimensões de 3,4 $\mathrm{m}$ de largura por 18,0 m de comprimento, com declividade transversal de 2\% (Figura 1). Uma canaleta foi construída ao longo da lateral mais baixa da plataforma, com a finalidade de coletar e retirar da plataforma a água residuária e a água de abastecimento aplicada pelos gotejadores. A unidade de controle para bombeamento da água residuária de suinocultura foi constituída por um reservatório de 7,0 m³ , uma 
peneira com tela metálica de $47 \mu \mathrm{m}$ e um conjunto motobomba de $3 \mathrm{cv}$. Essa peneira permitiu a remoção dos sólidos suspensos, principalmente de pelos de suínos e de óleos e graxas presentes na água residuária de suinocultura para minimizar os agentes físicos de obstrução no filtro de discos de do sistema de irrigação. A outra unidade de controle para o bombeamento de água de abastecimento foi composta por um reservatório de $6,0 \mathrm{~m}^{3}$, um conjunto motobomba de $3 \mathrm{cv}$ e um filtro de discos com aberturas de $130 \mu \mathrm{m}$. Na plataforma, foram montadas quatro unidades de irrigação, sendo que cada uma delas possuía uma válvula reguladora de pressão de $105 \mathrm{kPa}$, uma linha de derivação de PVC com diâmetro nominal de $32 \mathrm{~mm}$ e nove linhas laterais de polietileno. Em cada unidade de irrigação, foram testados três tipos de gotejadores, apresentados na Tabela 1. As características dos gotejadores foram obtidas de catálogos técnicos fornecidos pelos fabricantes e medidas com auxílio de parquímetro. Na linha de derivação de cada unidade de irrigação, foram inseridas três linhas laterais para cada um dos três tipos de gotejadores. As linhas laterais apresentaram $18 \mathrm{~m}$ de comprimento, sendo posicionadas sobre o piso da bancada experimental, que não possuía declividade nessa direção. Em todas as linhas laterais, marcaram-se 22 emissores para a medição da vazão, ao longo do período experimental.

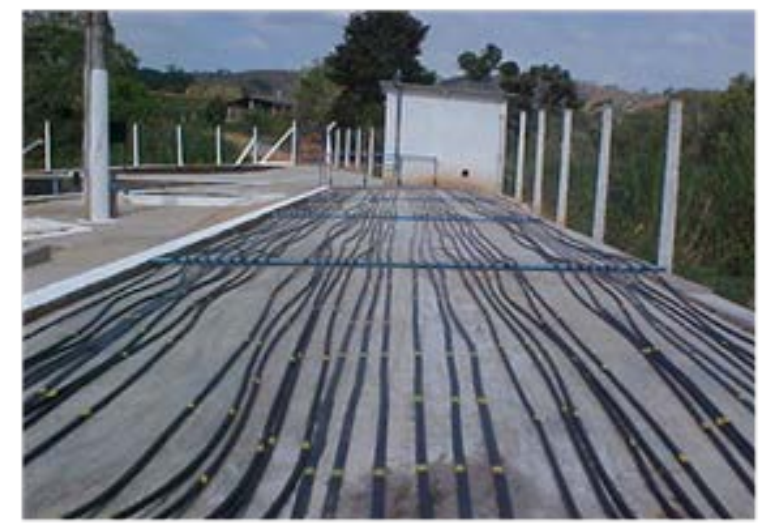

(a)

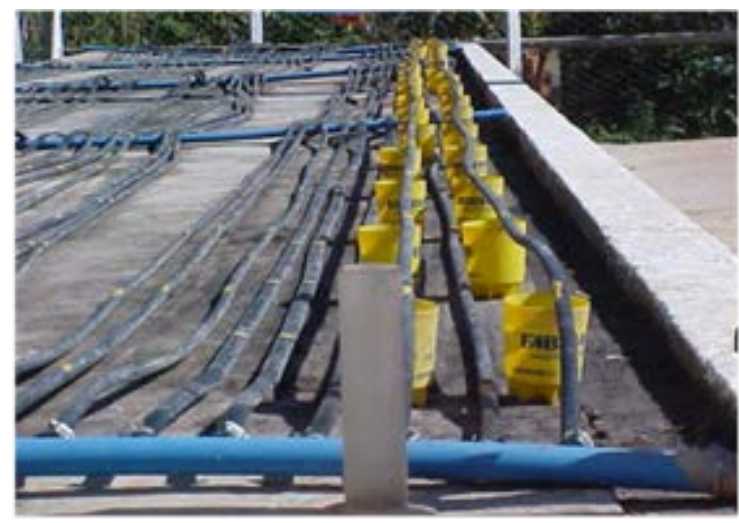

(b)

FIGURA 1. Bancada experimental, destacando-se a plataforma de testes (a) e o ensaio para medição de vazão dos gotejadores (b). Testing bench, highlighting the test platform (a) and test for measurement of drippers flow rate (b).

TABELA 1. Características dos gotejadores $(G)$ utilizados nos ensaios experimentais: dispositivo de autocompensação (DA), vazão nominal (Q), área do orifício (A), comprimento do labirinto (L), coeficiente de variação de fabricação $\left(\mathrm{CV}_{\mathrm{f}}\right)$ e faixa de pressão recomendada $(\mathrm{P})$. Characteristics of drippers $(\mathrm{G})$ used in experimental tests: the autocompensation device (DA), the nominal flow rate $(Q)$, the orifice area $(A)$, the labyrinth length $(L)$, coefficient of manufacturing variation $\left(C_{f}\right)$ and pressure range recommended $(\mathrm{P})$.

\begin{tabular}{ccccccc}
\hline $\mathbf{G}$ & $\mathbf{D A}$ & $\begin{array}{c}\mathbf{Q} \\
\left(\mathbf{L ~ h} \mathbf{~}^{\mathbf{1}}\right)\end{array}$ & $\begin{array}{c}\mathbf{A} \\
\left.\mathbf{( m m}^{\mathbf{2}}\right)\end{array}$ & $\begin{array}{c}\mathbf{L} \\
(\mathbf{m m})\end{array}$ & $\begin{array}{c}\mathbf{C V} \\
\mathbf{( \% )}\end{array}$ & $\begin{array}{c}\mathbf{P} \\
(\mathbf{k P a})\end{array}$ \\
\hline G1 & Não & 2,00 & 4,45 & 327 & $\leq 3$ & $80-300$ \\
G2 & Não & 1,70 & 1,86 & 176 & $\leq 3$ & $40-100$ \\
G3 & Sim & 3,60 & 2,54 & 44 & $\leq 4$ & $80-350$ \\
\hline
\end{tabular}

Na Figura 2, estão ilustrados os tipos de gotejadores testados: gotejador não autocompensante, cilíndrico, interno e com labirinto tortuoso (G1); gotejador não autocompensante, plano, interno e com labirinto tortuoso (G2), e gotejador autocompensante cilíndrico, interno, com labirinto tortuoso e amplo filtro secundário (G3). 


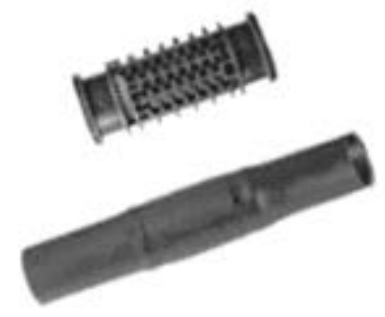

G1

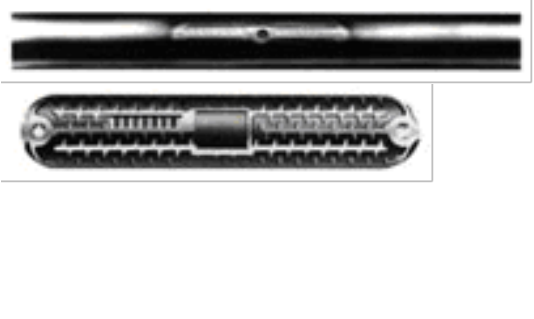

G2

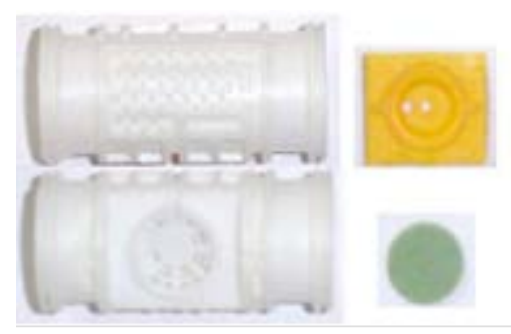

G3

FIGURA 2. Gotejadores G1, G2 e G3 utilizados nos ensaios. Drippers G1, G2 and G3 used on tests.

Na condução dos ensaios experimentais, foram utilizadas as seguintes proporções de tempo de irrigação com água residuária de suinocultura (ARS) e água de abastecimento (AA): a) 1E3A = uma hora de aplicação de ARS seguida de três horas de aplicação de AA; b) 2E2A = duas horas de aplicação de ARS seguida de duas horas de aplicação de AA; c) 3E1A = três horas de aplicação de ARS seguida de uma hora de aplicação de AA; e d) 4E = quatro horas de aplicação de ARS. A alternância de proporções de tempo de irrigação com ARS e com AA foi motivada pela interferência da aerobiose e da anaerobiose das águas residuárias no processo de obstrução de gotejadores, como descrito por PUIG-BARGUÉS et al. (2005) e BATISTA et al. (2011). Neste sentido, a ARS representa a condição de anaerobiose, enquanto a AA representa a condição de aerobiose.

As unidades de irrigação funcionaram quatro horas por dia até completar 160 h, seguindo a metodologia proposta por CUNHA et al. (2006), em que um tempo de operação de 144 h foi suficiente para proporcionar a obstrução de gotejadores que operaram com água residuária. Os dados de vazão foram obtidos dos 22 gotejadores identificados por linha lateral, seguindo a recomendação de CAPRA \& SCICOLONE (1998), que recomendaram, no mínimo, 16 gotejadores para a avaliação do desempenho hidráulico de sistemas de irrigação por gotejamento com problemas de entupimento. A vazão de cada gotejador foi determinada coletando-se o volume aplicado durante três minutos. Com o uso de válvulas reguladoras de pressão nas quatro unidades de irrigação, a pressão de serviço foi mantida em $105 \pm 5 \mathrm{kPa}$ e medida, diariamente, com manômetro graduado de 0 a $400 \mathrm{kPa}$. No tempo de operação inicial $(0 \mathrm{~h})$, quando não houve obstrução, as variações de vazão entre os gotejadores encontraram-se na faixa de $\pm 7 \%$ estabelecida na NBR ISO 9261 (ABNT, 2006).

O monitoramento da qualidade da água residuária de suinocultura foi realizado a cada $20 \mathrm{~h}$, simultaneamente com a determinação da vazão dos gotejadores, totalizando nove amostragens até o encerramento dos ensaios experimentais, no tempo de operação de 160 h. A água residuária de suinocultura foi proveniente da UTARS, sendo a maior frequência do monitoramento atribuída às elevadas oscilações das características físico-químicas e biológicas do efluente em detrimento do manejo da alimentação, vacinação, vermifugação e limpeza das instalações. No monitoramento da qualidade da água de abastecimento, as amostragens foram realizadas a cada $80 \mathrm{~h}$, devido à menor variação das características físico-químicas e biológicas. A água de abastecimento foi oriunda da rede de abastecimento de água da Companhia de Saneamento de Minas Gerais-COPASA.

Determinaram-se as características físico-químicas e biológicas da água residuária de suinocultura e água de abastecimento, seguindo as recomendações do Standard Methods for the Examination of Water and Wastewater (RICE et al., 2012). No Laboratório de Qualidade da Água, do Departamento de Engenharia Agrícola da UFV, foram medidos os valores do potencial hidrogeniônico $(\mathrm{pH})$, com peagâmetro de bancada. Determinaram-se, também, as concentrações da demanda bioquímica de oxigênio $\left(\mathrm{DBO}_{5}{ }^{20}\right)$ pelo método iodométrico (processo Winkler); dos sólidos suspensos (SS) pelo método gravimétrico com a utilização de membranas de fibra de vidro 
(0,45 $\mu \mathrm{m}$ de diâmetro de poro); e dos sólidos totais (ST) pelo método gravimétrico. As concentrações dos sólidos dissolvidos (SD) foram obtidas pela diferença entre as concentrações dos sólidos totais (ST) e dos sólidos suspensos (SS), sendo a temperatura do fluido (T) medida in loco com um termômetro de mercúrio, com precisão de $0,5{ }^{\circ} \mathrm{C}$. Nos Laboratórios de Matéria Orgânica e Resíduos e de Espectrofotometria Atômica, ambos do Departamento de Solos da UFV, foram determinadas as concentrações de ferro $(\mathrm{Fe})$, manganês $(\mathrm{Mn})$, cálcio $\left(\mathrm{Ca}^{2+}\right)$, magnésio $\left(\mathrm{Mg}^{2+}\right)$ e enxofre (S), por espectrofotometria de absorção atômica. As análises microbiológicas foram feitas no Laboratório de Microbiologia de Alimentos do Departamento de Microbiologia da UFV. Os resultados foram expressos em unidades formadoras de colônia por mililitro (UFC mL ${ }^{-1}$ ).

O experimento foi conduzido em esquema de parcelas subsubdivididas, tendo nas parcelas as proporções de tempo de irrigação com água residuária de suinocultura e água de abastecimento (1E3A, 2E2A, 3E1A e 4E), nas subparcelas os tipos de gotejadores (G1, G2 e G3) e nas subsubparcelas os tempos das avaliações $(0 ; 20 ; 40 ; 60 ; 80 ; 100 ; 120 ; 140$ e 160 h), em delineamento inteiramente casualizado, com três repetições. Na análise de variância, empregou-se o teste $\mathrm{F}$, em nível de 1\% de probabilidade. Os modelos de regressão foram escolhidos com base na significância dos coeficientes de regressão, utilizando-se do teste t, em nível de até $10 \%$; no coeficiente de determinação; e no processo em estudo. As médias foram comparadas, utilizando-se do teste de Tukey, a 5\% de probabilidade. Na realização das análises estatísticas, utilizou-se do programa computacional Sisvar 5.1 Build 72 (FERREIRA, 2011).

\section{Qualidade da água residuária de suinocultura e da água de abastecimento}

Na Tabela 2, está apresentada a classificação do risco de obstrução dos atributos físicoquímicos e biológicos da água residuária de suinocultura (ARS) e da água de abastecimento (AA), caracterizadas a cada 20 e 80 h, respectivamente, até completar o tempo de operação de 160 h.

Com relação ao risco de obstrução de gotejadores, o pH da água residuária de suinocultura foi classificado como moderado, pois encontrou-se dentro da faixa de 7,0 a 7,5 (NAKAYAMA et al., 2006), divergindo de SILVA et al. (2013) e LIU \& HUANG (2009), que encontraram risco severo de obstrução desse atributo para água residuária do processamento da castanha de caju e esgoto sanitário tratado. Semelhantemente, o valor médio do $\mathrm{pH}$ da água de abastecimento, também, encontrou-se dentro da faixa de 7,0 a 7,5, sendo o risco de obstrução de gotejadores classificado como moderado, corroborando o resultado obtido LIU \& HUANG (2009) para água de abastecimento.

A concentração média de sólidos suspensos presente na água residuária de suinocultura foi superior a $100 \mathrm{mg} \mathrm{L}^{-1}$, representando risco severo de obstrução de gotejadores, conforme a recomendação de NAKAYAMA et al. (2006), ultrapassando, também, o limite de $50 \mathrm{mg} \mathrm{L}^{-1}$ estabelecido por CAPRA \& SCICOLONE (2007) para sistemas de irrigação por gotejamento que operam com águas residuárias, com níveis aceitáveis de uniformidade de distribuição de efluente. $\mathrm{Na}$ água de abastecimento, houve ausência de sólidos suspensos, não representando risco de obstrução de gotejadores, corroborando LIU \& HUANG (2009), que não detectaram a presença de sólidos suspensos na água de abastecimento utilizada nos ensaios com sistemas de irrigação por gotejamento. 
TABELA 2. Classificação do risco de obstrução dos atributos físico-químicos e biológicos da água residuária de suinocultura (ARS) e da água de abastecimento (AA), caracterizadas a cada 20 e 80 h, respectivamente, até completar o tempo de operação de 160 h. Hazard classification of obstruction of the physico-chemical and biological attributes for swine wastewater (ARS) and supply water (AA) characterized every 20 and $80 \mathrm{~h}$, respectively, to complete the operation time of $160 \mathrm{~h}$.

\begin{tabular}{|c|c|c|c|c|c|c|}
\hline \multirow{2}{*}{ Características } & \multirow{2}{*}{ ARS } & \multicolumn{2}{|c|}{$\begin{array}{l}\text { Risco de entupimento de } \\
\text { gotejadores }\end{array}$} & \multirow[t]{2}{*}{ AA } & \multicolumn{2}{|c|}{$\begin{array}{l}\text { Risco de entupimento de } \\
\text { gotejadores }\end{array}$} \\
\hline & & {$\left[1^{*}\right]$} & {$\left[2^{*}\right]$} & & {$\left[1^{*}\right]$} & {$\left[2^{*}\right]$} \\
\hline$\overline{\mathrm{pH}^{*}}$ & $7,54 \pm 0,14$ & Moderado & & $7,12 \pm 0,07$ & Moderado & \\
\hline $\mathrm{SS}^{*}$ & $333 \pm 60,56$ & Severo & & $0 \pm 0$ & Nenhum & \\
\hline $\mathrm{SD}^{*}\left(\mathrm{mg} \mathrm{L}^{-1}\right)$ & $\begin{array}{l}1370 \pm \\
284,39\end{array}$ & Moderado & & $54 \pm 9$ & Baixo & \\
\hline $\mathrm{S}\left(\mathrm{mg} \mathrm{L}^{-1}\right)$ & $45,40 \pm 10,69$ & Severo & & $0 \pm 0$ & Nenhum & \\
\hline $\mathrm{Fe}^{*}\left(\mathrm{mg} \mathrm{L}^{-1}\right)$ & $5,50 \pm 2,92$ & Severo & & $0 \pm 0$ & Nenhum & \\
\hline $\mathrm{Mn}^{*}\left(\mathrm{mg} \mathrm{L}^{-1}\right)$ & $0,84 \pm 0,76$ & Moderado & & $0 \pm 0$ & Nenhum & \\
\hline $\mathrm{Ca}^{2+*}\left(\mathrm{mmol}_{\mathrm{c}} \mathrm{L}^{-1}\right)$ & $4,85 \pm 0,93$ & & Baixo & $0,53 \pm 0,06$ & & Baixo \\
\hline $\operatorname{Mg}^{2+*}\left(\operatorname{mmol}_{\mathrm{c}} \mathrm{L}^{-1}\right)$ & $2,81 \pm 0,37$ & & Moderado & $0,21 \pm 0,01$ & & Baixo \\
\hline $\mathrm{DBO}_{5}{ }^{20^{*}}\left(\mathrm{mg} \mathrm{L}^{-1}\right)$ & $602 \pm 252,43$ & & & $10 \pm 0,59$ & & \\
\hline $\mathrm{PB}^{* *}\left(\mathrm{UFC} \mathrm{mL}^{-1}\right)$ & $\begin{array}{c}9,7 \times 10^{5} \pm \\
5,62\end{array}$ & Severo & & $\begin{array}{c}1,5 \times 10^{3} \pm \\
2,71\end{array}$ & Baixo & \\
\hline
\end{tabular}

Nota: $\mathrm{SS}=$ sólidos suspensos; $\mathrm{SD}=$ sólidos dissolvidos; $\mathrm{S}=$ enxofre; $\mathrm{Fe}=$ ferro total; $\mathrm{Mn}=$ manganês total; $\mathrm{Ca}^{2+}=$ cálcio; $\mathrm{Mg}^{2+}=$ magnésio; $\mathrm{DBO}_{5}=$ Demanda Bioquímica de Oxigênio; PB = população bacteriana; e UFC = unidades formadoras de colônias. * Média e Desvio-padrão aritmético das características. ${ }^{* *}$ Média e Desvio-padrão geométrico da característica. $\left(1^{*}\right)$ NAKAYAMA et al. (2006). (2*) CAPRA \& SCICOLONE (1998).

Para os sólidos dissolvidos da água residuária de suinocultura, o risco de obstrução de gotejadores foi classificado como moderado, pois o valor médio situou-se dentro da faixa limite de 500 a $2.000 \mathrm{mg} \mathrm{L}^{-1}$ (NAKAYAMA et al., 2006). No entanto, esse resultado foi inferior ao valor médio de $2.344 \mathrm{mg} \mathrm{L}^{-1}$ de sólidos dissolvidos determinado por SILVA et al. (2013) para água residuária do processamento da castanha de caju. Na água de abastecimento, a concentração média de sólidos dissolvidos foi inferior ao valor limite de $500 \mathrm{mg} \mathrm{L}^{-1}$ proposto por NAKAYAMA et al. (2006), representando baixo risco de obstrução de gotejadores. Além disso, esse resultado foi menor que o valor médio de $339 \mathrm{mg} \mathrm{L}^{-1}$ de sólidos dissolvidos obtido por LIU \& HUANG (2009) em água de abastecimento.

O teor médio de enxofre da água residuária de suinocultura ultrapassa o limite de $0,1 \mathrm{mg} \mathrm{L}^{-1}$ proposto por AYERS \& WESTCOT (1999), classificando o risco de obstrução de gotejadores como severo, enquanto na água de abastecimento, não houve a presença de enxofre, indicando ausência de risco de obstrução de gotejadores, corroborando o resultado apresentado por LIU \& HUANG (2009) para água de abastecimento.

O valor médio do ferro total presente na água residuária de suinocultura superou o valor limite de $1,5 \mathrm{mg} \mathrm{L}^{-1}$ estabelecido por NAKAYAMA et al. (2006), que classificam o risco de obstrução de gotejadores como severo, corroborando os resultados obtidos por BATISTA et al. (2011) para esgotos domésticos preliminar, secundário e terciário. Na água de abastecimento, não foi detectada a presença de ferro total, indicando que não existe risco de obstrução de gotejadores para essa 
característica, contrariando os resultados de LIU \& HUANG (2009), que constataram baixo risco de obstrução de gotejadores para esse atributo na água de abastecimento.

O manganês da água residuária de suinocultura representa moderado risco de obstrução de gotejadores, pois seu valor médio encontrou-se dentro da faixa limite de 0,1 a $1,5 \mathrm{mg} \mathrm{L}^{-1}$ (NAKAYAMA et al., 2006), corroborando os resultados obtidos por SILVA et al. (2013) com água residuária do processamento da castanha de caju. O teor médio do manganês na água de abastecimento não foi detectado, indicando que não existe risco de obstrução de gotejadores, confrontando os resultados obtidos por LIU \& HUANG (2009), que detectaram baixo risco de obstrução desse atributo na água de abastecimento.

O valor médio do cálcio na água residuária de suinocultura foi menor que $11,89 \mathrm{mmol}_{\mathrm{C}} \mathrm{L}^{-1}$ obtido por SILVA et al. (2013) em água residuária do processamento da castanha de caju. De acordo com CAPRA \& SCICOLONE (1998), esse valor médio é inferior ao limite de 12,5 $\mathrm{mmol}_{\mathrm{C}}$ $\mathrm{L}^{-1}$ que classifica o risco de obstrução de gotejadores como baixo. Para a água de abastecimento, o teor de cálcio foi inferior ao valor limite de $12,5 \mathrm{mmol}_{\mathrm{C}} \mathrm{L}^{-1}$, classificando o risco de obstrução de gotejadores como baixo (CAPRA \& SCICOLONE, 1998), corroborando os resultados obtidos por LIU \& HUANG (2009) para esse atributo na água de abastecimento.

A concentração média do magnésio na água residuária de suinocultura foi menor que o valor de 4,32 $\mathrm{mmol}_{\mathrm{C}} \mathrm{L}^{-1}$ determinado por SILVA et al. (2013) na água residuária do processamento da castanha de caju. O valor médio do magnésio encontrou-se dentro da faixa limite de 2,0 a 7,3 mmol $_{\mathrm{c}} \mathrm{L}^{-1}$ que classifica o risco de obstrução de gotejadores como moderado (CAPRA \& SCICOLONE, 1998). Na água de abastecimento, o teor médio de magnésio foi menor que o valorlimite de 2,0 $\mathrm{mmol}_{\mathrm{C}} \mathrm{L}^{-1}$, indicando baixo risco de obstrução de gotejadores, corroborando LIU \& HUANG (2009).

O resultado obtido para $\mathrm{DBO}_{5}{ }^{20}$ da água residuária de suinocultura foi superior ao limite de $25 \mathrm{mg} \mathrm{L}^{-1}$, estabelecido por CAPRA \& SCICOLONE (2007) para ótima uniformidade de aplicação de efluente via sistemas de irrigação por gotejamento. Mas na água de abastecimento, o valor médio da $\mathrm{DBO}_{5}{ }^{20}$ foi inferior ao limite de $25 \mathrm{mg} \mathrm{L}^{-1}$ proposto por CAPRA \& SCICOLONE (2007).

Na água residuária de suinocultura, o nível médio populacional de bactérias foi superior ao limite de 5,0 x $10^{4}$ UFC por mL, que classifica o risco de obstrução de gotejadores como severo (NAKAYAMA et al., 2006). Esse resultado foi superior ao nível populacional médio de bactérias, de 4,03 x10³ UFC por mL apresentado por LIU \& HUANG (2009) para a água residuária sanitária tratada. A água de abastecimento representa baixo risco de obstrução de gotejadores, tendo em vista que o valor médio da população bacteriana foi inferior ao valor limite de $1,0 \times 10^{4}$ UFC por mL (NAKAYAMA et al., 2006). No entanto, esse resultado foi superior ao valor médio de $6,6 \times 10^{1}$ UFC por mL apresentado por LIU \& HUANG (2009) para água de abastecimento.

\section{Vazão de gotejadores mediante proporções de tempo de irrigação com água residuária de suinocultura e água de abastecimento}

Nos tempos de funcionamento inicial (0h) e final (160 h), os valores de vazão das unidades de irrigação com gotejador G1 submetidas às proporções de tempo de irrigação com água residuária de suinocultura e água de abastecimento 1E3A, 2E2A, 3E1A e 4E foram de 2,33 e 1,96 L h ${ }^{-1}$; 2,32 e $0,97 \mathrm{~L} \mathrm{~h}^{-1}$; 2,34 e 1,01 $\mathrm{L} \mathrm{h}^{-1}$; e 2,31 e 1,95 L h${ }^{-1}$, apresentando reduções nos valores de vazão de 16; 58; 57 e 16\%, respectivamente (Figura 3). Para 1E3A e 2E2A, essas reduções de vazão foram superiores ao valor de 20\% obtido por DAZHUANG et al. (2009) após 160 h de operação de gotejador similar, operando com água residuária sanitária secundária. Verificou-se, nas unidades de irrigação dotadas do gotejador G1, submetidas aos níveis 2E2A e 3E1A, a tendência de decréscimo dos valores de vazão, ao longo do tempo de funcionamento. Esses resultados corroboram os obtidos por BATISTA et al. (2011), que após 500 h de operação de sistemas de irrigação por gotejamento constataram que as águas residuárias sanitárias preliminar, secundária e terciária proporcionam reduções na vazão dos gotejadores das unidades de irrigação de 62; 22 e 61\%, respectivamente. 


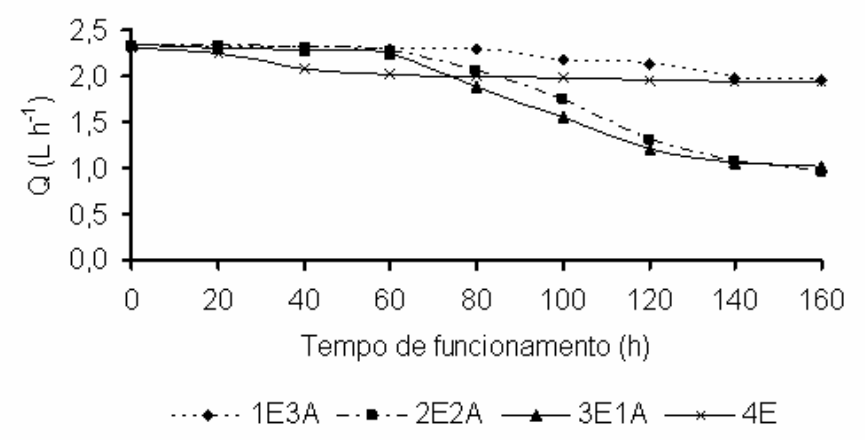

(a)

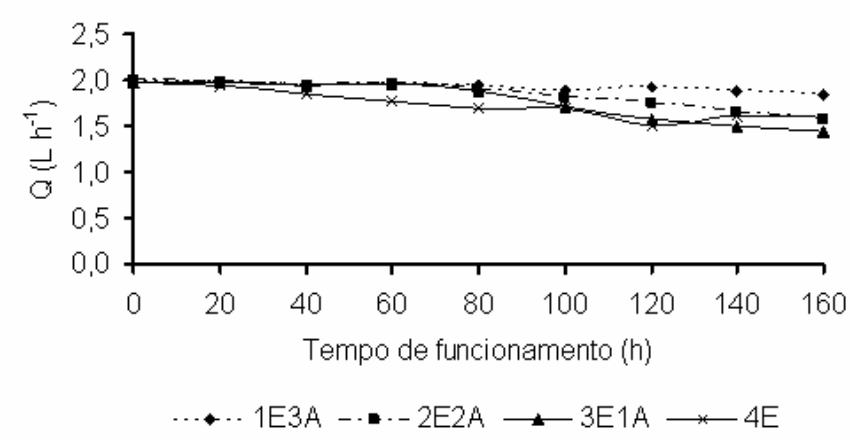

(b)

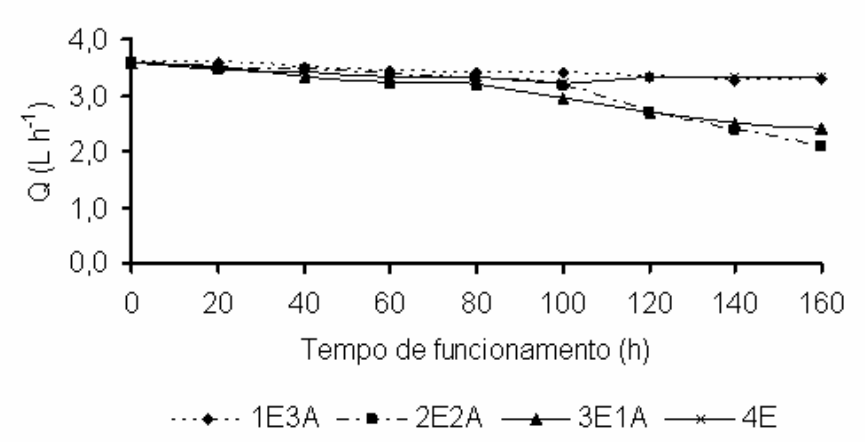

(c)

FIGURA 3. Valores médios de vazão (Q), ao longo do tempo de funcionamento, nas unidades de irrigação com gotejador G1 (a), G2 (b) e G3 (c), submetidas às proporções de tempo de irrigação com água residuária de suinocultura e água de abastecimento (1E3A, $2 \mathrm{E} 2 \mathrm{~A}, 3 \mathrm{E} 1 \mathrm{~A}$ e $4 \mathrm{E})$. Mean values of flow rate $(\mathbf{Q})$ along the of operation time on irrigation dripper units G1 (a), G2 (b) and G3 (c) submitted to the proportion of irrigation time with swine wastewater and supply water (1E3A, 2E2A, 3E1A and 4E).

De acordo com os resultados (Figura 3b), constatou-se que as alterações nos valores de vazão com gotejador G2 foram mais acentuadas nas unidades de irrigação submetidas às proporções de tempo de irrigação com água residuária de suinocultura e água de abastecimento 2E2A, 3E1A e 4E do que na unidade submetida à proporção de tempo de irrigação 1E3A. Nos tempos de funcionamento de $0 \mathrm{~h}$ e $160 \mathrm{~h}$, as unidades de irrigação submetidas às proporções de tempo de irrigação com água residuária de suinocultura e água de abastecimento 1E3A, 2E2A, 3E1A e 4E apresentaram valores de vazão de 1,99 e 1,85 $\mathrm{L} \mathrm{h}^{-1}$; 1 ,99 e 1,58 $\mathrm{L} \mathrm{h}^{-1}$; 1,99 e 1,44 L h${ }^{-1}$; e 1,99 e $1,50 \mathrm{~L} \mathrm{~h}^{-1}$, respectivamente (Figura 3b). Comparando-se os tempos de funcionamento, constatou-se que as reduções nos valores de vazão foram de 7; 21; 28 e 25\%. Excetuando-se a proporção de tempo de irrigação 1E3A, as reduções nas vazões foram superiores ao valor de $13 \%$ obtido por LIU \& HUANG (2009) após 160 h de operação de gotejador similar com água residuária sanitária de sistema de lodo ativado. As unidades de irrigação com gotejador G3 submetidas às proporções de 
tempo de irrigação com água residuária de suinocultura e água de abastecimento 1E3A, 2E2A, 3E1A e 4E apresentaram valores de vazão nos tempos de funcionamento $0 \mathrm{~h}$ e $160 \mathrm{~h}$, de 3,59 e 3,31 $\mathrm{L} \mathrm{h}^{-1}$; 3,58 e 2,08 $\mathrm{L} \mathrm{h}^{-1}$; 3,60 e 2,40 L h${ }^{-1}$; e 3,57 e 3,32 $\mathrm{L} \mathrm{h}^{-1}$, respectivamente (Figura 3c). Nesse caso, as reduções nos valores de vazão foram de 8; 42; 33 e 8\%. Para 2E2A, 3E1A, essas reduções foram semelhantes às obtidas por DURAN-ROS et al. (2009) após 1.000 horas de operação de gotejador similar com água residuária sanitária terciária. Em geral, as alterações nos valores de vazão das unidades submetidas aos níveis 2E2A e 3E1A foram mais acentuadas do que nas submetidas aos níveis 1E3A e 4E, devido ao oxigênio dissolvido presente na água de abastecimento, que pode ter estimulado o desenvolvimento de microrganismos aeróbios com maior potencial de formação biofilme, corroborando PUIG-BARGUÉS et al. (2005) e BATISTA et al. (2011). Comparando as proporções de tempo de irrigação 1E3A e 4E, notou-se que a redução de vazão foi menor em 4E, devido à anaerobiose do efluente que não estimula o desenvolvimento de bactérias aeróbias especializadas na formação de biofilme com maior potencial de obstrução de gotejadores, tais como Enterobacter, Clostridium, Flavobacterium, Vibro, Brevibacterium, Micrococcus e Bacillus, além de não favorecer o desenvolvimento de bactérias que oxidam o ferro (Gallionella, Leptothrix, Toxothrix, Crenothrix e Sphaerotilus) e o enxofre (Thiothrix nivea e Beggiatoa sp) (NAKAYAMA et al., 2006).

Estão apresentadas na Tabela 3 as equações de regressão que melhor se ajustaram aos dados de vazão em função do tempo de funcionamento, para cada nível de tipos de gotejadores e cada nível de proporção de tempo de irrigação com água residuária de suinocultura e água de abastecimento.

TABELA 3. Equações de regressão ajustadas à variável vazão (Q) em função dos tempos de operação (T), para cada nível de tipos de gotejadores e proporções de tempo de irrigação com água residuária de suinocultura e água de abastecimento. Regression equations adjusted to the flow rate variable $(Q)$ as a function of operation time (T), for each level of dripper kinds and proportions of irrigation time with swine wastewater and supply water.

\begin{tabular}{cccc}
\hline Gotejador & Proporção de água & \multicolumn{1}{c}{ Equação de regressão } & R $^{2}$ \\
\hline & 1E3A & $\hat{\mathrm{Q}}=2,324+0,000466^{\mathrm{ns}} \mathrm{T}-0,0000181^{* *} \mathrm{~T}^{2}$ & 0,97 \\
2E2A & $\hat{\mathrm{Q}}=2,370-0,0000599^{\mathrm{ns}} \mathrm{T}-0,0000604 * * \mathrm{~T}^{2}$ & 0,96 \\
& 3E1A & $\hat{\mathrm{Q}}=2,430-0,00422^{* *} \mathrm{~T}-0,0000356^{* *} \mathrm{~T}^{2}$ & 0,95 \\
& 4E & $\hat{\mathrm{Q}}=2,317-0,00598^{* *} \mathrm{~T}+0,0000234^{* *} \mathrm{~T}^{2}$ & 0,97 \\
\hline \multirow{2}{*}{ 1E3A } & $\hat{\mathrm{Q}}=1,992-0,000789 * * \mathrm{~T}$ & 0,86 \\
& 2E2A & $\hat{\mathrm{Q}}=1,990+0,0000441^{\mathrm{ns}} \mathrm{T}-0,0000168^{* *} \mathrm{~T}^{2}$ & 0,98 \\
& 3E1A & $\hat{\mathrm{Q}}=2,009-0,000606^{\mathrm{ns}} \mathrm{T}-0,0000205^{* *} \mathrm{~T}^{2}$ & 0,96 \\
& 4E & $\hat{\mathrm{Q}}=2,015-0,00525^{* *} \mathrm{~T}+0,0000155^{* *} \mathrm{~T}^{2}$ & 0,91 \\
\hline \multirow{2}{*}{ 1E3A } & $\hat{\mathrm{Q}}=3,610-0,00316^{* *} \mathrm{~T}+0,00000728^{\mathrm{ns}} \mathrm{T}^{2}$ & 0,96 \\
& 2E2A & $\hat{\mathrm{Q}}=3,524+0,00230^{*} \mathrm{~T}-0,0000720^{* *} \mathrm{~T}^{2}$ & 0,98 \\
& 3E1A & $\hat{\mathrm{Q}}=3,605-0,00479 * * \mathrm{~T}-0,0000189 * * \mathrm{~T}^{2}$ & 0,98 \\
& 4E & $\hat{\mathrm{Q}}=3,564-0,00490 * * \mathrm{~T}+0,0000221^{* *} \mathrm{~T}^{2}$ & 0,86
\end{tabular}

\footnotetext{
**, * e ${ }^{\text {ns }}$ significativos a 1 e $5 \%$ de probabilidade e não significativo a $10 \%$ de probabilidade, respectivamente, pelo teste t.
} 
O modelo quadrático foi o que melhor representou a relação entre os dados de vazão e o tempo de funcionamento das unidades de irrigação dotadas do gotejador G1, submetidas às proporções de tempo de irrigação 1E3A, 2E2A, 3E1A e 4E. Esses resultados diferem dos obtidos por BATISTA et al. (2011), em que a equação de regressão tipo linear foi a que melhor se ajustou aos dados de vazão de gotejadores em função do tempo de operação com água residuária sanitária preliminar, secundária e terciária. Constatou-se que o modelo linear foi o que melhor representou a relação entre os dados de vazão e o tempo de funcionamento da unidade de irrigação dotada do gotejador G2, submetida à proporção de tempo de irrigação 1E3A. No entanto, o modelo quadrático foi o que melhor representou a relação entre os dados de vazão e o tempo de funcionamento das unidades de irrigação submetidas a proporções de tempo de irrigação com água residuária de suinocultura e água de abastecimento 2E2A, 3E1A e 4E. Esses resultados corroboram o obtido por BATISTA et al. (2009),em que houve relação linear entre a vazão e o tempo de operação de sistemas de irrigação por gotejamento abastecidos com água residuária doméstica terciária para gotejador não autocompensante. Nas unidades de irrigação dotadas do gotejador G3, submetidas às proporções de tempo de irrigação 1E3A, 2E2A e 3E1A, o modelo quadrático foi o que melhor se ajustou aos dados de vazão em função do tempo de funcionamento. No trabalho realizado por BATISTA et al. (2009), houve relação linear entre a vazão e o tempo de operação de sistemas de irrigação por gotejamento, abastecidos com água residuária doméstica terciária para gotejador autocompensante. Observando-se os valores negativos dos coeficientes angulares dos modelos propostos (quadrático e linear), notou-se que ocorre uma tendência de redução na vazão dos gotejadores à medida que se passa o tempo de utilização da água residuária de suinocultura.

Na Tabela 4, estão contidos os valores médios da variável vazão para o fator gotejador dentro de cada nível de tempo de funcionamento e de proporções de tempo de irrigação com água residuária de suinocultura e água de abastecimento.

Ocorreram alterações significativas nos valores de vazão a partir de $40 \mathrm{~h}$, divergindo do resultado obtido por BATISTA et al. (2010), que obtiveram redução de apenas $4 \%$ na vazão média de gotejares que operaram durante 120 h com esgoto doméstico terciário. Constatou-se, também, que as proporções de tempo de irrigação com água residuária de suinocultura e água de abastecimento 1E3A e 4E minimizaram o entupimento dos gotejadores, enquanto as proporções de tempo de irrigação 2E2A e 3E1A o potencializaram. No nível 1E3A, o tempo de aplicação de água foi maior em relação aos demais níveis, e isso pode ter causado a remoção de sólidos do interior dos gotejadores e das linhas laterais, e a redução da adesão microbiana nas paredes do equipamento, contribuindo, assim, para a atenuação do entupimento. Em relação ao nível 4E, a minimização do entupimento foi atribuída à escassez de oxigênio dissolvido no efluente que, provavelmente, diminuiu a produção de subprodutos da atividade microbiana e, consequentemente, a formação de biofilme. Nos níveis 2E2A e 3E1A, os menores tempos de aplicação de água não foram suficientes para a remoção dos sólidos do interior do equipamento, além de favorecerem o desenvolvimento do biofilme, devido ao fornecimento de oxigênio dissolvido aos microrganismos aeróbios, corroborando os trabalhos apresentados por PUIG-BARGUÉS et al. (2005) e BATISTA et al. (2011). 
TABELA 4. Valores médios da variável vazão $\left(\mathrm{Q}\right.$, em $\left.\mathrm{L} \mathrm{h}^{-1}\right)$ para o fator gotejador dentro de cada nível de tempo de funcionamento e de proporções de tempo de irrigação com água residuária de suinocultura e água de abastecimento. Mean values of the flow rate variable $\left(Q, L h^{-1}\right)$ for the drip factor within each level of operating time and proportions of time irrigation with swine wastewater and supply water.

\begin{tabular}{|c|c|c|c|c|c|}
\hline \multirow{2}{*}{ Tempo de funcionamento } & \multirow{2}{*}{ Gotejador } & \multicolumn{4}{|c|}{ Proporção de água* } \\
\hline & & 1E3A & 2E2A & 3E1A & $4 \mathrm{E}$ \\
\hline \multirow[t]{3}{*}{ (hI) } & G1 & 2,33a & 2,32a & $2,34 a$ & $2,31 a$ \\
\hline & G2 & 1,99a & $1,99 a$ & 1,99a & $1,99 a$ \\
\hline & G3 & $3,59 a$ & $3,58 a$ & $3,60 a$ & $3,57 a$ \\
\hline \multirow{3}{*}{20} & G1 & $2,32 a$ & $2,32 a$ & $2,32 a$ & $2,24 a$ \\
\hline & G2 & $1,97 a$ & $1,98 \mathrm{a}$ & 1,99a & $1,94 a$ \\
\hline & G3 & $3,58 \mathrm{a}$ & $3,47 a$ & $3,52 a$ & $3,46 a$ \\
\hline \multirow{3}{*}{40} & G1 & $2,32 a$ & $2,31 a$ & $2,29 a$ & $2,08 b$ \\
\hline & G2 & $1,95 \mathrm{a}$ & $1,94 a$ & $1,94 a$ & $1,84 \mathrm{a}$ \\
\hline & G3 & $3,50 \mathrm{a}$ & $3,48 a$ & 3,33a & $3,42 \mathrm{a}$ \\
\hline \multirow{3}{*}{60} & G1 & $2,28 a$ & $2,26 a$ & $2,24 a$ & $2,01 b$ \\
\hline & G2 & $1,97 a$ & $1,96 a$ & 1,96a & $1,77 b$ \\
\hline & G3 & 3,43a & 3,37ab & $3,22 b$ & 3,34ab \\
\hline \multirow{3}{*}{80} & G1 & $2,28 a$ & $2,05 b$ & $1,89 b$ & $1,99 \mathrm{~b}$ \\
\hline & G2 & $1,95 \mathrm{a}$ & $1,91 \mathrm{a}$ & $1,88 \mathrm{a}$ & $1,69 b$ \\
\hline & G3 & $3,40 \mathrm{a}$ & $3,29 \mathrm{ab}$ & $3,22 b$ & $3,35 a b$ \\
\hline \multirow{3}{*}{100} & G1 & $2,18 a$ & $1,74 \mathrm{c}$ & $1,57 \mathrm{~d}$ & $1,98 b$ \\
\hline & G2 & $1,88 \mathrm{a}$ & 1,80ab & $1,70 \mathrm{~b}$ & $1,70 \mathrm{~b}$ \\
\hline & G3 & 3,39a & 3,16b & $2,94 \mathrm{c}$ & 3,22ab \\
\hline \multirow{3}{*}{120} & G1 & $2,13 a$ & $1,31 b$ & $1,22 b$ & $1,95 a$ \\
\hline & G2 & $1,92 \mathrm{a}$ & $1,75 a$ & $1,57 \mathrm{~b}$ & $1,49 b$ \\
\hline & G3 & 3,33a & $2,69 b$ & $2,69 b$ & $3,34 a$ \\
\hline \multirow{3}{*}{140} & G1 & $1,99 a$ & $1,08 \mathrm{~b}$ & $1,06 \mathrm{~b}$ & $1,94 a$ \\
\hline & G2 & $1,88 \mathrm{a}$ & $1,65 b$ & $1,50 \mathrm{~b}$ & $1,61 b$ \\
\hline & G3 & $3,28 \mathrm{a}$ & $2,38 b$ & $2,52 b$ & $3,34 a$ \\
\hline \multirow{3}{*}{160} & G1 & $1,96 a$ & $0,97 \mathrm{~b}$ & $1,01 \mathrm{~b}$ & $1,95 a$ \\
\hline & G2 & $1,85 \mathrm{a}$ & $1,58 \mathrm{~b}$ & $1,44 \mathrm{~b}$ & $1,60 \mathrm{~b}$ \\
\hline & G3 & 3,31a & $2,08 c$ & $2,40 b$ & 3,32a \\
\hline
\end{tabular}

* Médias seguidas de, pelo menos, uma mesma letra minúscula nas linhas para cada proporção de água não diferem entre si, a 5\% de probabilidade, pelo teste de Tukey.

No tempo de funcionamento de 40 h, os valores de vazão das unidades de irrigação com gotejador G1, submetidas a proporções de tempo de irrigação com água residuária de suinocultura e água de abastecimento 1E3A, 2E2A e 3E1A, diferiram do valor de vazão da unidade de irrigação submetida à proporção de tempo de irrigação 4E (Tabela 4); no tempo de funcionamento de $60 \mathrm{~h}$, os valores de vazão das unidades de irrigação dotadas dos gotejadores G1 e G2, submetidas às proporções de tempo de irrigação 1E3A, 2E2A e 3E1A, diferiram do valor de vazão da unidade de irrigação submetida à proporção de tempo de irrigação 4E, enquanto o valor de vazão da unidade de irrigação com gotejador G3, submetida à proporção de tempo de irrigação 1E3A, foi diferente do valor de vazão da unidade de irrigação submetida à proporção de tempo de irrigação 3E1A; e, no tempo de funcionamento de 160 h, os valores de vazão das unidades de irrigação com gotejadores G1, submetidas às proporções de tempo de irrigação 1E3A e 4E, diferiram dos valores de vazão das unidades de irrigação submetidas às proporções de tempo de irrigação 2E2A e 3E1A, o valor de vazão da unidade de irrigação com gotejador G2, submetida à proporção de tempo de irrigação 1E3A, diferiu dos valores de vazão das unidades de irrigação submetidas às proporções de tempo de 
irrigação 2E2A, 3E1A e 4E, e os valores de vazão das unidades de irrigação com gotejador G3, submetidas às proporções 1E3A, 2E2A e 3E1A, diferiram entre si.

\section{CONCLUSÕES}

A combinação dos gotejadores G1 e G3 com as proporções de tempo de irrigação 1E3A e 4E minimizou o processo de entupimento, sendo as reduções nos valores de vazão foram de 16 e $8 \%$, respectivamente, após 160 h de operação das unidades de irrigação.

\section{AGRADECIMENTOS}

Ao Conselho Nacional de Desenvolvimento Científico e Tecnológico (CNPq), pela bolsa de doutorado.

\section{REFERÊNCIAS}

ABNT - Associação Brasileira de Normas Técnicas. Equipamentos de irrigação agrícola Emissores e tubos emissores - Especificações e métodos de ensaio. ABNT NBR ISO 9261. São Paulo: ABNT, 2006. 17p.

AYERS, R. S.; WESTCOT, D. W. A qualidade da água na agricultura. Traduzida por H.R. Gheyi, J.F. de Medeiros, F.A.V. Damaceno. Campina Grande: UFPB, 1999. 153 p. (Estudos FAO, 29).

BATISTA, R. O.; SOARES, A. A.; MOREIRA, D. A.; FEITOSA, A. P.; BEZERRA, J. M. Influência de diferentes qualidades de esgoto doméstico na vazão de gotejadores. Revista Caatinga, Mossoró, v. 24, n. 3, p. 128-134, jul./set., 2011.

BATISTA, R. O.; SOUZA, J. A. R.; FERREIRA, D. C. Influência da aplicação de esgoto doméstico tratado no desempenho de um sistema de irrigação. Revista Ceres, Viçosa, MG, v. 57, n.1, p. 18-22, jan./fev., 2010.

BATISTA, R. O.; SOARES, A. A.; MARIN, O. L. Z.; SOUZA, J. A. R.; LEITE, C. V.; MOREIRA, D. A. Taponamiento de goteros y del filtro de discos con agua residual sanitaria de una laguna de maduración. Revista Facultad Nacional de Agronomia, Medellín, v. 62, n. 1 p. 49574966, 2009.

CAPRA, A.; SCICOLONE, B. Recycling of poor quality urban wastewater by drip irrigation systems. Journal of Cleaner Production, Amsterdam, v. 15, n. 16, p.1529-1534, 2007.

CAPRA, A.; SCICOLONE, B. Water quality and distribution uniformity in drip/trickle irrigation systems. Journal of Agricultural Engineering Research, London, v. 70, n. 4, p. 355-365, 1998.

CUNHA, F. F.; MATOS, A. T.; BATISTA, R. O.; LO MONACO, P. A. Uniformidade de distribuição em sistemas de irrigação por gotejamento utilizando água residuária da despolpa dos frutos do cafeeiro. Acta Scientiarum. Agronomy, Maringá, v. 28, n. 1, p. 143-147, jan./mar., 2006.

DAZHUANG, Y.; ZHIHUI, B.; ROWAN, M.; LIKUN, G.; SHUMEI, R.; PEILING, Y. Biofilm structure and its influence on clogging in drip irrigation emitters distributing reclaimed wastewater. Journal of Environmental Sciences, Beijing, v. 21, n. 6, p. 834-841, 2009.

DURAN-ROS, M.; PUIG-BARGUE'S, J.; ARBAT, G.; BARRAGA'N, J.; RAMI'REZ DE CARTAGENA, F. Effect of flushing frequency on emitter clogging in microirrigation with effluents. Agricultural Water Management, Amsterdam, v. 96, n.1, p. 67-79, 2009

FERREIRA, D. F. Sisvar: a computer statistical analysis system. Ciência e Agrotecnologia, Lavras, v. 35, n.6, p. 1039-1042, nov./dec., 2011.

LIU, H.; HUANG, G. Laboratory experiment on drip emitter clogging with fresh water and treated sewage effluent. Agricultural Water Management, Amsterdam, v. 96, n.5, p. 745-756, 2009. 
MERRIAM, J. L.; KELLER, J. Farm irrigation system evaluation: a guide for management. Logan: Utah State University, 1978. 271p.

NAKAYAMA, F. S.; BOMAN, B. J.; PITTS, D. Maintenance. In: LAMM, F. R.; AYARS, J. E.; NAKAYAMA, F. S. (Ed.). Microirrigation for crop production: Design, Operation, and Management. Amsterdam: Elsevier, 2006. cap. 11, p. 389 - 430.

PUIG-BARGUÉS, J.; ARBAT, G.; ELBANA, M.; DURAN-ROS, M.; BARRAGÁN, J.; RAMÍREZ DE CARTAGENA, F.; LAMM, F. R. Effect of flushing frequency on emitter clogging in microirrigation with effluents. Agricultural Water Management, Amsterdam, v. 97, n. 6, p. 883891, 2010.

PUIG-BARGUÉS, J.; ARBAT, G.; BARRAGÁN, J.; RAMÍREZ DE CARTAGENA, F. Hydraulic performance of drip irrigation subunits using WWTP efluents. Agricultural Water Management, Amsterdam, v. 77, n. 1-3, p.249-262, 2005.

RICE, E. W.; BAIRD, R. B.; CLESCERI, A. D. Standard methods for the examination of water and wastewater. 22. ed. Washington: APHA, AWWA, WPCR, 2012. 1496p.

RODRIGUES, L. S.; SILVA, I. J.; ZOCRATO, M. C. O.; PAPA, D. N.; SPERLING, M. V.; OLIVEIRA, P. R. Avaliação de desempenho de reator UASB no tratamento de águas residuárias de suinocultura. Revista Brasileira de Engenharia Agrícola e Ambiental, Campina Grande, v. 14, n. 1, p. 94-100, jan., 2010.

SILVA, K. B.; SILVA JÚNIOR, M. J.; BATISTA, R. O.; SANTOS, D. B.; BARBOSA FILHO, S. Desempenho de gotejadores operando com efluente da castanha de caju sob distintas pressões de serviço. Revista Ceres, Viçosa, MG, v. 60, n.3, p. 339-346, mai./jun., 2013.

ZHANG, J.; ZHAO, W.; TANG, Y.; LU. B. Anti-clogging performance evaluation and parameterized design of emitters with labyrinth channels. Computers and Electronics in Agriculture, Amsterdam, v. 74, n. 1, p.59-65, 2010. 